\title{
Chapter 8 \\ The Rhythms of Shipboard Life: Work, \\ Hierarchy, Occupational Culture \\ and Multinational Crews
}

\author{
Helen Sampson
}

\section{Introduction}

Several words repeatedly crop up when you ask a seafarer working in the international cargo fleet to describe a life at sea: 'boring', is one; 'lonely' is another; and the word 'sacrifice' is used very frequently as well. Most contemporary seafarers are recruited from developing economies where well-paid opportunities for work ashore are scarce and, if they can be found at all, are only available to highly skilled or qualified personnel. As a result, the money that can be earned at sea by both officers and ratings is often unparalleled and this encourages people to seek work as a seafarer when they are young. It also keeps many of them coming back to sea as they get older (as described so vividly by Baum-Talmor in Chap. 5) despite having come to grips with some of the rather unglamorous aspects of the job.

However, from the outset some people can't cope with the conditions found on board. Many leave after their first or second experiences of 'sea-time' as cadets (Gould 2010). They speak of the institutionalized regimes, the bullying, the monotony, and the isolation, as 'intolerable'. As the observations of Hill (1972) attest, this is not a new phenomenon. However, as modern life and the expectations of young people have changed it is likely that some of the disadvantages of a life at sea have come to be even less acceptable to contemporary seafarers than they once were to their predecessors. In 2010, some of Gould's young interviewees struggled with captains who bullied them, physical abuse, loneliness, and depression. One described his experiences of a ship from which he was hugely relieved to ultimately 'escape'. He told Gould that:

[The cook] threatened me with a knife, he was absolutely blind drunk. When he was cooking he used to drink, it was awful really. So after that episode I, well, after that incident I just

\footnotetext{
H. Sampson $(\square)$

Seafarers International Research Centre, School of Social Sciences, Cardiff University, Cardiff, Wales, UK

e-mail: sampsonh@cf.ac.uk
} 
went to my room and cried. And I've never, I've never actually cried in my life, I was just so, so scared and so, so lonely. And my company couldn't care less, they didn't even phone in, or send anything. [...] Well I, I just could not wait to leave the ship, I could not wait to get off that, off that ship. No one was there to say, you know good luck and see you later, or anything. So, I got off the ship and then I got back home. I was so glad to be home. (Sam quoted in Gould 2010, p. 174).

The institutionalized nature of the ship, its isolation, the occupational culture on board and the complexities of legal jurisdiction, all combine to make ships unique workplace settings which carry both threats and opportunities for seafarers. They are first and foremost workplace settings where work dominates almost all other concerns. However, they are also spaces where strong hierarchies determine all activities (work-based and leisure-based) and where occupational cultures and multinational crewing practices have a strong influence on behaviour. This chapter describes some of these features of contemporary ships and provides a sense of the context of daily shipboard life. It is based upon the insight that has been acquired as the result of ethnographic work undertaken over a period of 21 years.

\section{The Dominance of Work}

One of the central reasons why many seafarers describe life on board as 'boring' is because it is overwhelmingly dominated by work. Work is 'what the ship does' and an idle ship 'haemorrhages' cash at a phenomenal rate. Ship operators are driven to maximize the productivity of their vessels which essentially means keeping them at sea, and on the move, for as much of their time as possible (Sampson and Wu 2003). They are driven by financial imperatives to keep the ships loaded and in transit and this, in turn, causes them to maintain pressure on their seafarers to keep to schedules, load and off-load cargoes as swiftly as possible, and maintain vessels in seaworthy condition.

For seafarers this essentially means that: they get very little leisure time ashore; that they may be at work at any time of the day or night; and that the majority of them work seven days a week (Ellis et al. 2012). In 2016, the average number of days spent in port (this means within port limits and not necessarily on a berth) was reported by Marine Traffic to be 1.37 days across all vessel types. The average for container vessels was lower with an average of just 0.87 days in port (UNCTAD 2017). Given that this is an average and that many ships will arrive in a port during the hours of darkness it is evident that many seafarers have little, if any, opportunity for shore-leave. Once their vessel is berthed the port-based duties of seafarers are onerous with a requirement for some of them to work six hours on and six hours off in shifts that involve duties relating to cargo, stores, maintenance and security. In general, seafarers work above average hours with a normal working day described as just over ten hours long once berthed in port and almost nine and a half hours long when at sea (Ellis et al. 2012). Much of the remainder of a seafarers' time is spent eating, sleeping and undertaking domestic chores such as laundry. If there is an email 
or internet connection on board (which is frequently not the case) then some of their non-working time is also spent 'chatting' with family or friends via email, SMS, and (more rarely) video link. Otherwise, seafarers may socialize intermittently whilst watching a DVD, or they may engage in physical activity if there is gym equipment on board (usually in the form of a fixed cycle, weights or a treadmill). This generally represents the extent of their non-work shipboard life.

In terms of work, the vessel is divided into three 'departments' namely the 'deck' department, the 'engine' department and the 'galley'. On most contemporary vessels, the galley crew is skeletal in nature and consists of just two crew members-a chief cook and a messman. Between them these two people cook for the whole crew, keep the galley and the food storage spaces clean, manage the garbage, order provisions and maintain cleanliness in communal spaces (messrooms and alleyways) and sometimes the cabins of senior officers. They are amongst the hardest working of all the seafarers on board, working split shifts seven days a week for months at a time.

The remaining crew are fairly evenly divided between the deck and engine departments. On the 'deck side' the officers are generally involved in navigating the vessel, maintaining stability, and stowing and offloading the cargo. The captain is the highest ranking officer and beneath him there is usually a chief officer, a second officer, and a third officer. There may also be a cadet. The bosun occupies a position in the hierarchy that is sandwiched between the officers and the ratings. The bosun and deck ratings are mainly involved in vessel maintenance and cleaning. The bosun usually meets with the chief officer each morning to report back on the tasks that have been accomplished by his team and to receive instructions relating to new ones. He then goes on to assign jobs to the ratings who work with him on maintenance jobs such as washing decks, chipping and painting.

In the engine room, a chief engineer oversees operations and undertakes administration and 'paperwork'. The second engineer is usually the overall supervisor and each engineer has responsibility for different pieces of engine equipment (generators or purifiers, for example, or the main engine itself). Ratings assist the engineering officers and as such there is usually at least one wiper and one motorman. Fitters may also be attached to the engine department and, as with the deck department, there may be one or more cadets at any given time.

There are other positions that are associated with very particular kinds of ship. On a tanker a pumpman is employed, and on a refrigerated cargo ship there is normally a specialist 'reefer' engineer who takes care of the refrigeration systems. On container vessels, when large numbers of refrigerated containers are on board, there may be several electrical engineers monitoring and maintaining them to ensure that valuable cargoes are not damaged as a result of the malfunction of cooling systems. These officers are part of the regular crew, however, from time to time so-called 'riding crew' may work on board for limited periods of time to accomplish specific maintenance tasks which are too time consuming for the usual crew to take care of. These additional members of the crew are often quite segregated from the other seafarers on board. This is partly a consequence of their transient presence and partly due to the fact that there are normally at least two of them and they are usually of the 
same nationality as each other and may regularly work together. From time to time a company may also provide additional support in the form of an extra third officer to assist officers with arduous navigational schedules where it has been demonstrated that it is not possible to meet the requirements for work-rest hours without additional resources.

All seafarers understand the primacy of work on board and all have generally joined the vessel to make money. Ratings welcome overtime if it will attract extra pay and resent officers who restrict their hours in ways that limit their capacity to earn extra cash on board. Officers are concerned to get good reports from their seniors and to achieve promotion and therefore put in any extra hours which they feel are necessary to achieve this and senior officers (captains and chief engineers) are frequently paid bonuses that are linked to key performance indicators (KPIs). They are also subject to a great deal of pressure from ashore if, and when, things go wrong in terms of damage to machinery, delays to port schedules, accidents, or detentions by inspectors in ports. Many seafarers also find that keeping themselves busy with work on board is a good way of staving off the boredom which is associated with their very limited and institutionalized experience. When combined, these factors generally produce an attitude to work that was nicely summed up by a seafarer posting to a public web forum about life at sea in the 'old' days. He wrote:

We were trained at sea by our superiors that it didn't matter if you were sick or dying on your feet. It didn't matter if you were injured or genuinely ill. 'get your **** down below. You have a watch to keep. Your god is 'the job' [sic]. http://www.shipsnostalgia.com/ showthread.php?t=48587 (accessed 24/11/19)

Whilst this engineer felt that 'times' had 'changed' this attitude is still hugely pervasive on board (Sampson 2013). 'Your God is the job!' nicely sums it up.

\section{Hierarchies and the Social Order}

Not only do work activities dominate the lives of seafarers on board but occupational rank dominates all aspects of the shipboard social order and all the interactions between seafarers on board. The captain makes every decision pertaining to social matters such as 'parties', 'shore leave' and access to the ship's 'shop' known as the 'bond' or 'slop chest'. Many also liaise a great deal with the galley staff, setting the overall 'policy' for meals on board and deciding on provisioning-what should be bought and where. Some captains consult with chief engineers on such matters and some have a less collaborative approach. However, everyone is very clear that ultimately the captain is 'king': that what the captain says goes (Sampson 2013).

Chief engineers are also socially powerful figures on board as they are of the same 'rank' as the captain, carrying the same number of 'stripes', but they do not have the same overall responsibility for the vessel and its activities. Seafarers defer to chief engineers and to captains in similar ways but recognize that it is the captain who 'rules the roost' at the end of the day. On a recent voyage I witnessed a clear example 
of this understanding in action. The captain and chief engineer did not enjoy a close relationship and they were quite often seen to be at odds with each other. On one occasion, the air-conditioning was switched off by the chief engineer to allow for a procedure to take place in the engine room. As a result, the chief engineer ordered all the outer doors of the accommodation block to be left open so that there was adequate ventilation. The captain did not agree with this and was particularly concerned to ensure that the outer doors (which were watertight and as such played an integral part in the ship's safety design) were closed at night. I was on the bridge when the officer on watch instructed the watchman to go around the vessel and to close all of the outer doors on every deck. He went further telling him that if the chief engineer saw him and said anything about his actions he must reply that it was 'captain's orders' and must continue to close all doors. The seafarers in this situation displayed their understanding of the fact that the captain and chief engineer were in disagreement about the best course of action but they were concomitantly in no doubt at all over whose orders must be obeyed.

In general, chief engineers and captains do their best to get along together and the happiest ships are usually those where the senior officers enjoy a good rapport with each other as well as with other crew members. However, rapport with crew members is usually seen by officers as something which must be constrained and kept within certain limits. Officers are acutely aware of the need to maintain their authority on board so that their orders will be unquestioningly followed. Whilst the personal management style of captains varies considerably, there is nonetheless a strongly shared understanding amongst them of the need for captains to maintain a social distance between themselves and the remainder of the crew. Chief engineers and more junior officers also share this view-but usually to a lesser extent. Generally speaking, the most junior of the officers on board (particularly cadets) feel the most at liberty to freely socialize with ratings. In this context, it is interesting that many senior officers feel that it is much easier for them to preserve the necessary social distance with more junior ranks when they do not share a nationality. For this reason, multinational crews are often preferred over single nationality crews (Sampson 2013). Once again this emphasizes the primacy of work on board as it is precisely because social relationships are less easy-going (and enjoyable) amongst multinational crews that seafarers regard these contexts as the easiest ones within which to maintain a 'suitable' professional distance.

Regardless of the precise nature of the relationships between the individuals on board, the social life that is possible is, in any case, very limited. There are a variety of reasons for this. Firstly crews are very small and many crewmembers work split shifts. The galley crew wake up early each morning to prepare breakfast. They then clear up and prepare lunch. After lunch they may take a short break before preparing dinner and they are usually the first crewmembers to go to bed. Deck officers work on shifts (08.00-12.00, 12.00-16.00, and 16.00-20.00 repeating the same hours again through the night and morning respectively-20.00-00.00, 00.00-04.00, 04.00-08.00) and they are accompanied by watchmen (particularly in the hours of darkness and periods of poor visibility) in the form of able seamen (ABs) who may alternate the additional night shifts that are required. Engineering officers on vessels 
with so-called 'unmanned' engine rooms (which do not require constant overnight attendance) nevertheless rotate night watches. In the course of these they are tasked with visiting the engine room and carrying out any necessary activity whenever an engine alarm sounds (this can be expected to happen several times a night even on well-maintained modern vessels). Finally, the senior officers may all be called upon to work late hours at any time in response to urgent tasks such as demands for information from shore-side managers (Sampson et al. 2016). Consequently the opportunity for social activities is constrained from the outset by the rhythms of work. However there are also other factors which contribute to the extent to which modern vessels are 'all about work'. They include: company rules pertaining to social activities such as sports, barbecues and alcohol consumption; the limited space that is provided for leisure activities; seafarers' fears about accidents; and (relatedly) the extent to which seafarers are constantly aware of the need to stave off the effects of fatigue.

Alcohol consumption on board is restricted by international law. The 2010 Manila Amendments to the International Convention on Standards of Training, Certification and Watchkeeping, (STCW) 1978 establish limits on permitted levels of blood alcohol for any seafarers while 'performing designated safety, security and marine environmental duties' (Spark 2016). Prosecution for contravention in the UK (for example) may result in fines and/or prison sentences of up to two years. For many companies, however, such limits are insufficient. In response to fears about accidents at sea resulting in costly pollution incidents and damage to infrastructure/ vessels many companies have introduced 'no alcohol' policies on board what are known as 'dry ships'. Large companies such as Maersk have banned alcohol on all of their vessels (Karstensen 2016) and many tanker and gas carriers are also designated by companies as 'dry' in line with charter party agreements imposed by cargo owners and/or their own requirements. The findings from a questionnaire survey undertaken in 2016 indicate that 58\% of contemporary cargo ships are 'dry' (Sampson et al. 2017). This represents a significant change from the past.

For crew members who are culturally inclined towards an association between alcohol and relaxation these limits have had a profound impact on the social life on board. This is perhaps summed up best by seafarers themselves and one posting to a public online forum for merchant seafarers just before Christmas in 2012 put it like this:

Present company went [to a daily limit of] four beers, then reduced to two then this year went dry. What limited social scene there was given the multinational demographic, it has virtually disappeared now. Our non-alcoholic beer and soft drinks are free, but that's little compensation. Happy feckin Christmas! (sic). (http://www.shipsnostalgia.com/showthread. php?t=48587 accessed 29/01/2018)

However it is not only the absence of a 'bar' and the chance of a 'chinwag' over a cold beer that has killed much of the social life that once existed on board. There are other rules that have been introduced by companies which have had an impact too. It was formerly commonplace for seafarers to enjoy the ritual of a barbecue on deck if, and when, a weekend fell in the midst of an ocean passage. Today many companies 
have banned the barbecue in line with their safety policies much to the chagrin of seafarers. I sailed with one such company in 2000. The captain on board was generally a great supporter of his company but when he described the barbecue ban to me, and the fears underpinning it (largely - fire risk due to potential flying sparks), he laughed bitterly and contemptuously whilst gesturing upwards towards the smoke stack 'haven't they seen what comes out of the funnel' he exclaimed. I looked upwards and sure enough witnessed a stream of small glowing particles rising into the air from the ships' 'exhaust'. Some sports have also been banned alongside the barbecue. Basketball was banned on a tanker I sailed with in 2006 because too many seafarers were adjudged to have sustained finger injuries whilst playing. More pervasively, other facilities, such as swimming pools, have just been removed from ships and have thereby been 'designed out' of seafarers' shipboard lives (Sampson and Ellis 2019).

A further constraint on the shipboard social lives' of seafarers is the very basic matter of physical space. The prioritization of cargo space over accommodation block space has led to a squeeze on communal spaces on board. Messrooms which were once large enough to accommodate whole crews for social events are now too small to do so. Indeed the last vessel I sailed with did not have a room which was large enough to accommodate the whole crew for a first aid training drill or for debriefings following training. The crew squeezed into the deck office as best they could but some were forced to sit in the alley way, such was the limited space. This is not untypical in the modern fleet.

Finally, seafarers themselves may limit their own social lives on board as a result of their need to protect themselves from fatigue. The shipboard motion, disturbance from vibration, uncomfortable mattresses, light 'pollution', and shift work all combine to make sleep on board a precious commodity. Many seafarers recognize the critical importance of achieving adequate levels of rest and spend their free time trying to sleep or undertaking domestic tasks. They may also attempt to preserve their physical health by using weight machines, fixed cycles or other 'gym' equipment where this is provided. Most of these activities are inherently solitary and militate against the development of any kind of vibrant shipboard social life.

Within this constrained context it is still possible for particular ships to be characterized as 'happy' ships by seafarers. These are usually vessels where the captain permits and encourages social activities such as bingo, 'horse racing', and similar 'games'. In general, and perhaps universally, the shipboard occupational hierarchy is such that without the captain's encouragement and endorsement such activities do not occur. The same applies to the scheduling of social events such as 'parties' to mark birthdays on board or significant cultural occasions such as Christmas. It also applies to barbecues where these remain permitted by companies and to the filling and use of swimming pools where these exist. Captains may even determine use of gym equipment by having some of it moved to areas where it may be exclusively used by themselves or perhaps by other officers.

For many seafarers the captain is only one of a relatively long list of people who hold a position of authority over them on board. Deck ratings are subject to the authority of the bosun, the junior officers (deck and engine), the chief officer, the 
captain and the chief engineer. This means that the majority of their crewmates are in fact their superiors in rank and authority. For them, socialising in the presence of seniors is inevitably constrained and it may be avoided by some seafarers altogether for fear of attracting criticism. Hierarchy is also an issue when seafarers have the opportunity to enjoy shore-leave, as senior ranks do not cease to exercise their authority once ashore. This results in some seafarers choosing to go ashore alone rather than in company, simply to have a few brief hours when they feel free of 'surveillance' from managers and supervisors.

\section{Occupational Culture and Multinational Crews}

As previously noted, truly multinational crews are often popular amongst seafarers. However some crewing patterns are less effective than others in terms of both the work and the social life on board. Generally speaking where there are just two or three nationalities present on a ship there are associated challenges. These are considerably exacerbated when there is only a small group of people from a particular country. On the vessel Pollyanna, which I joined in 2013, I found that almost the entire crew was from India with just the chief engineer from elsewhere. In this instance, given the professional distance that he preferred to keep between himself and lower ranking seafarers, and his long experience at sea, the chief engineer was not unduly perturbed. Nevertheless for lower ranking seafarers, and particularly cadets, such skewed patterns of crewing can be highly unsatisfactory and associated with an extreme degree of social isolation.

Ships carrying only two or three nationalities may be characterized by strong divisions. Sometimes officers are all from one country and ratings are from another. However, in many cases the divide between nationalities does not match perfectly with the occupational divide between ratings and officers. In such circumstances ratings who share the same nationality as all the officers on board (but not the other ratings) may be accorded the temporary social status of officers (eating in the officers' mess etc.). By the same token on other vessels, where the demarcation between nationalities takes place further 'up' the hierarchical ladder, some officers may be 'demoted' to ratings' status in relation to social activities and life on board (Sampson 2013). This can have significant operational as well as social consequences, as it may often be in 'off-duty' time (e.g. during a lunch or coffee break) that significant information and knowledge is shared amongst officers. Junior officers who are relegated to the 'crew mess' as a result of their shared nationality with ratings will not be party to such information and as a result will not be as effective in contributing to the officer team as they could otherwise be. Equally, they may be encouraged to relate more to the ratings of their nationality than to the officers from whom they are socially excluded. This could result in the inappropriate sharing of confidential information which could contribute to undermining officer authority and/or respect and trust. Such practices are exacerbated by the tendency of crews, made up of just two or three nationalities, to frequently speak in their own languages 
rather than in the commonly understood international language of the sea-English. This can create a range of misunderstandings, a strong sense of suspicion and a crew which lacks a sense of solidarity and motivation (Sampson and Zhao 2003).

Mixed nationality crews may also be associated with discrimination and bullying, although bullying is by no means unique to multinational ships and is described by some seafarers as part of the overall occupational culture on board any ship. As one seafarer responding to a survey by the trade union Nautilus put it 'I think it will be nearly impossible to change the attitudes in the industry. Traditionally seafarers should be 'made of stern stuff' so we are almost expected to take a degree of bullying from superiors.' (Nautilus International 2010). Another suggested that 'Bullying, discrimination and harassment at sea has always been a problem in my experience even with all British crews' (Nautilus International 2010). Some seafarers go further in identifying single nationality crews as actually more prone to bullying or to its corollary-favouritism - than others (Sampson 2013) and it is revealing that in a study of stowaways and their strategies (Senu 2018) single nationality crews were often regarded as higher risk than mixed nationality crews. Some stowaways described how they felt that a single nationality crew was more prone to stick together in covering up abuses (of them) making violent treatment towards them more likely to occur. On the other hand, they felt that the slight mistrust between individual members of multinational crews was likely to protect them from maltreatment given that seafarers did not feel entirely confident about their crewmates' loyalty and the likelihood that such abuses would remain un-reported. This could imply that seafarers in genuinely mixed nationality crews receive a degree of protection resulting from a pervasive lack of certainty that the actions of potential bullies will be covered up by crewmates.

Whether it is more likely that bullying will take place on board a multinational vessel or a single nationality ship is a matter of debate. The pervasiveness of bullying reflects the degree to which it is embedded in the occupational culture of the sea. In such a culture, any individuals who are not well-established in the crew hierarchy by dint of their age/rank, gender or nationality are all potential objects of abuse and bullying. In this context, both women and cadets report a considerable amount of harassment, assault and abusive behaviour (Gould 2010; Belcher et al. 2003; Nautilus International 2010) which would not generally be tolerated in shorebased corporations. The shipboard occupational culture may exacerbate such behaviour as it discourages the telling of 'tales' about the misdemeanours of colleagues to managers and those ashore. On board my first vessel, I was instructed by a Swedish chief officer that 'what happens on the ship stays on the ship'-a lesson that is starkly brought home when reading the reports of incidents where seafarers have endured significant physical abuse from others but have chosen to remain silent about it. One telling example can be found in the case of the vessel Karin Schepers. The vessel grounded off Cornwall with the drunk captain at the helm. She was relatively quickly re-floated and sailed to her next port (Rotterdam) where she was met by MAIB inspectors. The inspectors removed her voice data recorder and retrieved recordings of activity on the bridge which had been deliberately left 'unsaved' by the captain. The recordings suggested that, prior to the grounding, the 
Ukrainian master had physically assaulted the Filipino second officer on the bridge punching him and causing him to audibly cry. Despite this, the MAIB report notes that:

\section{When interviewed by MAIB inspectors, the second officer had bruises and marks on his face and body that appeared to have been recently sustained. Subsequent analysis of the audio recordings from the VDR indicated an assault could have taken place on the bridge in the period before the grounding. In subsequent interviews, the second officer was unwilling to account for his injuries, and consequently this aspect of the events of the midnight to 0400 watch on 3 August remains unresolved (MAIB 2012, p. 17)}

Other aspects of occupational culture are less overtly unpleasant. Seafarers have a very strong 'work ethic' and there is little patience exercised with suspected malingerers (and indeed oftentimes with those in genuine distress). This results in a very strong sense of seafarers 'pulling together' on board with each individual fulfilling his or her duty to the best of their ability. In a crisis or emergency there is a culture of 'can do' on a ship which is frequently one of the characteristics which renders seafarers attractive to employers ashore (once their seagoing career is over). The occupational culture encourages seafarers to look favourably on colleagues who 'step up to the plate' in terms of effort, ingenuity and inventiveness when it comes to any operational matters. It also encourages stoicism, humour, and emotional toughness.

Many of these qualities are entwined with traditional European notions of masculinity and to that extent they doubtless reflect the historical roots of the merchant navy and the current European and OECD dominance of ownership of the global merchant fleet. Despite the move to developing countries in relation to labour supply, and the rampant surge of shipping in Asia, the shipping industry remains dominated by European/Russian and US owners. Notwithstanding the challenges of the Greek economy, Greece retains its longstanding position as the largest shipowning nation by deadweight tonnage and twelve of the top twenty ship owner countries are from Europe/USA/Russia (UNCTAD 2017). Germany dominates container shipping with a market share of $21 \%$ and Greece and Denmark occupy third and fourth positions respectively (China holds a market share of $9 \%$ and lies in second place). European norms associated with traditional forms of masculinity remain pervasive in this context, as the mostly male workforce moves from ship to ship carrying with it a widely shared idea of appropriate shipboard behaviour. These norms determine how seafarers live and work alongside each other despite having little personal knowledge of one and other. They are inculcated into cadets and constitute an important part of the 'apprenticeships' which nascent seafarers undergo (Gould 2010). 


\section{Conclusion}

There is little doubt that life for seafarers working in the 'deep-sea' cargo fleet is challenging. They endure physically difficult shipboard conditions for months on end: sacrificing sleep; being subject to continual vibration and noise; and existing in constrained physical spaces. They face dangerous weather conditions and a hazardous working environment. At regular, if not frequent, intervals seafarers are killed at sea aboard vessels which founder too quickly for safe evacuation (see for example the MAIB 2016 report on the loss Cemfjord with all hands) or explode (such as the case of the Sanchi an Iranian and Bangladeshi-crewed tanker which exploded and was lost with all hands off the coast of Shanghai in early 2018). In an article focussing on the environmental impact of the explosion of Sanchi, the Guardian newspaper correspondent Benjamin Haas marked its final disappearance with the following text:

The Iranian oil tanker Sanchi sank off the coast of Shanghai on Sunday, after a week of burning and sending plumes of smoke hundreds of metres into the air. Only three bodies of the 32 sailors were recovered. The ship was carrying 136,000 tons, or about 1 million barrels, of oil, that now threatens to pollute some of China's most important fishing waters. (Haas 2018)

Most seafarers prefer not to dwell on such tragic events. However, they rarely hesitate to suggest that being on board a ship is like being in a 'prison' frequently adding 'only worse' to their descriptions. They point to: the limited access to entertainment, recreation, and communication; the hierarchy and institutionalisation; the homesickness; and the constrained relationships between colleagues (Sampson and Ellis 2019). However, the challenges for some seafarers are more difficult than for others and this is an environment where it can be particularly difficult to be in a minority as either a woman, a cadet, or a sole representative of a particular nationality. Cargo ships in the international fleet are not suitable workplaces for the feinthearted. To withstand a life on board, seafarers require mental resilience, strong coping mechanisms, and a capacity to endure privation of both a physical and emotional nature.

\section{References}

Belcher, P., H. Sampson, M. Thomas, J. Veiga, and M. Zhao. 2003. Women Seafarers: Global Employment Policies and Practices. Geneva: International Labour Office. ISBN 92-2-1134911.

Ellis, N., H. Sampson, I. Acejo, L. Tang, N. Turgo, and Z. Zhao. 2012. Seafarer Accommodation on Contemporary Cargo Ships. Cardiff: SIRC, December. ISBN: 1-900174-43-X.

Gould, E. 2010. Towards a Total Occupation: A Study of UK Merchant Navy Officer Cadetship. $\mathrm{PhD}$ Thesis, Cardiff University and online at http://orca.cf.ac.uk/55023/1/U585412.pdf (accessed 24/11/2019).

Haas, B. 2018. 'East China Sea oil tanker disaster: what it means for the environment' The Guardian. https://www.theguardian.com/world/2018/jan/16/east-china-sea-oil-tanker-disasterwhat-it-means-for-the-environment (accessed 5/2/18). 
Hill, J. 1972. The Seafaring Career: A Study of the Forces Affecting Joining, Serving and Leaving the Merchant Navy. London: Centre for Applied Social Research, Tavistock Institute of Human Relations.

Karstensen, S. 2016. Policy Statements. Maersk Supply Services published online at http://www. maersksupplyservice.com/Lists/HSEQ/Attachments/2/Policy\%20UK.pdf (accessed 29/01/18).

MAIB. 2012. Report on the investigation of the grounding of Karin Schepers at Pendeen, Cornwall, UK on 2 August 2011 report No. 10/2012, May. Available on line at https://assets. publishing.service.gov.uk/media/547c6f83e5274a4290000033/KarinSchepers.pdf (accessed 24/11/2019).

- 2016. Report on the capsize and sinking of cement carrier Cemfjord in the Pentland Firth, Scotland with the loss of all eight crew on 2 and 3rd January 2015 report No. 8/2016, April. Available on line at https://assets.publishing.service.gov.uk/media/ 571760fee5274a22d300001e/MAIBInvReport_8_2016.pdf (accessed 24/11/2019).

Nautilus International. 2010. Report: Bullying, Discrimination\& Harassment Survey. London: Nautilus and on line at https://m.nautilusint.org/media/169246/Bullying-Discrimination-Harass ment-survey-2010.pdf (accessed 24/11/2019).

Sampson, H. 2013. International Seafarers and Transnationalism in the Twenty-First Century. Manchester: Manchester University Press.

Sampson, H., I. Acejo, N. Ellis, L. Tang, and N. Turgo. 2016. The Relationships Between Seafarers and Shore-Side Personnel: An Outline Report Based on Research Undertaken in the Period 2012-2016. Cardiff: SIRC, April. ISBN: 1-900174-48-0. On line at www.sirc.cf.ac.uk (accessed 24/11/2019).

Sampson, H., and N. Ellis. 2019. Seafarers' Mental Health and Wellbeing. Institution of Occupational Safety and Health (IOSH). https://www.iosh.com/media/6306/seafarers-mental-healthwellbeing-full-report.pdf (accessed 24/11/2019).

Sampson, H., N. Ellis, A. Acejo, and N. Turgo. 2017. Changes in Seafarers' Health 2011-2016: A Summary Report. Cardiff: SIRC, July. ISBN: 1-900174-49-9.

Sampson, H., and B. Wu. 2003. Compressing Time and Constraining Space: The Contradictory Effects of ICT and Containerization on International Shipping Labour. International Review of Social History 48 (S11): 123-152. https://doi.org/10.1017/S0020859003001299.

Sampson, H., and M. Zhao. 2003. Multilingual Crews: Communication and the Operation of Ships. World Englishes 22 (1): 31-45. https://doi.org/10.1111/1467-971X.00270.

Senu, A. 2018. The Global Assemblage of Multi-centred Stowaway Governance. PhD thesis, Cardiff University.

Spark, S. 2016. Safety feature: Why alcohol and ship crews don't mix. Fairplay January 29th 2018. https://fairplay.ihs.com/safety-regulation/article/4261711/safety-feature-why-alcohol-and-shipcrews-don-t-mix (accessed 30/1/2018).

UNCTAD. 2017. Review of Maritime Transport 2017. Geneva: UNCTAD. Available on line at http://unctad.org/en/PublicationsLibrary/rmt2017_en.pdf (accessed 24/11/2019).

Open Access This chapter is licensed under the terms of the Creative Commons Attribution 4.0 International License (http://creativecommons.org/licenses/by/4.0/), which permits use, sharing, adaptation, distribution and reproduction in any medium or format, as long as you give appropriate credit to the original author(s) and the source, provide a link to the Creative Commons licence and indicate if changes were made.

The images or other third party material in this chapter are included in the chapter's Creative Commons licence, unless indicated otherwise in a credit line to the material. If material is not included in the chapter's Creative Commons licence and your intended use is not permitted by statutory regulation or exceeds the permitted use, you will need to obtain permission directly from the copyright holder.

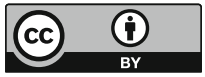

